\title{
Horticultural Therapy Programs Enhancing Quality of Life and Reducing Depression and Burden for Caregivers of Elderly with Dementia
}

\author{
Yong Hyun Kim ${ }^{1,2}$, Chul Soo Park ${ }^{3}$, Hwa-Ok Bae ${ }^{4}$, Eun Ji Lim ${ }^{5}$, Kyung Heui Kang ${ }^{6}$, Euy Sun Lee ${ }^{6}$, Su Hyeon Jo ${ }^{6}$, and Moo Ryong Huh H $^{7}$ \\ ${ }_{1}^{1}$ Post-doctoral associate, Department of Horticulture, Gyeongsang National University Jinju 52828, Korea \\ ${ }^{2}$ Doctoral student, Department of Social Welfare, Gyeongsang National University Jinju 52828, Korea \\ ${ }^{3}$ Professor, College of medicine, Gyeongsang National University, Jinju 52727, Korea \\ ${ }^{4}$ Professor, Department of Social Welfare, Gyeongsang National University Jinju 52828, Korea \\ ${ }^{5}$ Doctor of medicine, College of medicine, Gyeongsang National University, Jinju 52727, Korea \\ ${ }^{6}$ Public official, Haman Country Health Center, Haman 52046, Korea \\ ${ }^{7}$ Professor, Department of Horticulture, Gyeongsang National University Jinju 52828, Korea \\ 8 Institute of Agriculture \& Life Science, Gyeongsang National University, Jinju 52828, Korea
}

\section{ABSTRACT}

Background and objective: The problem that follows the increase of dementia patients is the burden of caregivers caring for dementia patients. The purpose of this study was to examine the effects of horticultural therapy programs improving the quality of life and reducing the depression and burden of caregivers of the elderly with dementia.

Methods: In this study, 19 caregivers of the elderly with dementia were selected, and the experiment was conducted by dividing the control group $(n=9)$ and the experimental group $(n=10)$ by random distribution. The experimental group was given eight horticultural therapy programs twice a week for a total of 4 weeks. Subjects were assessed using the depression(CES-D), quality of Life (WHOQOL-BREF), and care burden scales. The evaluation results were verified at a 95\% significance level using descriptive statistics, the Mann-Whitney $U$ test, and Wilcoxon signed-rank test.

Results: In the case of depression, the control group's score tended to increase, and the experimental group's score appeared to decrease, but it was not a statistically significant change. In the quality of life, the control group was not statistically significant, but scores decreased overall. On the other hand, in the experimental group, the general quality of life increased significantly from 11.60 to 14.20 points $(p=.02$ ), and the total quality of life increased to a marginally significant level from 61.59 points to 68.85 points $(p=.059)$. In the post-test of the total care burden score, a marginally significant difference was found between the control group (94.44 points) and the experimental group (82.50 points; $p=.079$ ).

Conclusion: This study confirmed the applicability to reduce the burden of caregiving and improve the deterioration of quality of life of the caregivers. In particular, the results will serve as an opportunity to confirm accessibility in a new way to support the caregiver of dementia patients by demonstrating the applicability of horticultural therapy at a time when problems such as the burden of supporting the caregiver are emerging as social problems.

Keywords: caregiver intervention, complementary and alternative treatment, human issues in horticulture, socio-horticulture, WHOQOL-BREF

\section{Introduction}

The increasing awareness of dementia as well as the rapid increase in the number of dementia patients in South Korea that followed the aging population caused the num- ber of dementia patients in South Korea to increase by 1.5 times in 2017 to 459,000 compared to 2013 (Statistics Korea, 2018). In particular, Korea is showing a higher prevalence of dementia compared to not only Western countries but also other Asian countries, and it is even in-

Received: March 31, 2020, Revised: May 5, 2020, Accepted: May 14, 2020

First author: Yong Hyun Kim, yonghyun@gnu.ac.kr, (1) https://orcid.org/0000-0003-1913-3041

*Corresponding author: Moo Ryong Huh, mrhuh@gnu.ac.kr, (1) https://orcid.org/0000-0001-8562-4901 
creasing (Kim et al., 2014).

The problem that follows the increase of dementia patients is the burden of caregivers caring for dementia patients. The Korean society emphasizes the caregiving duty of dementia patients' family based on the traditional Confucian ideas and familism, and thus the caregiver burden of family is greater than other cultures (Youn et al., 1999; Yoon et al., 2012). Furthermore, the burden of dementia caregivers also expands into the problem of the entire family. A family is an integrated open system in which its members affect one another through interdependence, and thus psychological and emotional problems such as the caregiving burden lead to conflicts among the members, thereby creating dysfunctional interactions such as dissatisfaction, criticism and mistrust among one another (Kwon, 1994, 2002).

Caregiving of dementia patients cause caregivers to discontinue their social activities to take care of dementia patients in addition to giving direct psychological burden, thereby making them face various burdens in everyday life such as loss of interpersonal relations and constraints on spare time (Yoo and Kim, 2004). Furthermore, dementia caregivers are stressed by cognitive behavioral problems of dementia patients such as change of character, wandering about, delusion and aggression, facing more severe depression than other caregiver groups (Cheng, 2017; Givens et al., 2014; Hernandez and Bigatti, 2010; Kuo et al., 2016), and are experiencing severe stress and deteriorated quality of life (QOL) due to restraints on daily life (D'Onofrio et al., 2015; Kim, 2017). These problems experienced by dementia caregivers cause them personal crises so severe as to refer to them as 'hidden patients', even leading to extreme results such as suicidal ideation and attempts (Parks and Novielli, 2003; J.Y. Kim et al., 2016). To solve these psychological and emotional problems, various psychotherapeutic intervention programs are carried out, such as psychoeducation, counseling and psychotherapy, mindfulness-based interventions, etc. These non-pharmacological interventions are proved to be effective in solving psychological and emotional problems of dementia caregivers such as depression, anxiety, stress and deteriorated QOL (Cheng et al., 2019; Cheong et al., 2020; Waelde et al., 2017).

Horticultural therapy is one of complementary and alter- native therapies and is proved by many studies as an effective intervention to solve psychological and emotional problems of subjects. According to Siu et al. (2020) who verified how much symptoms of mental diseases are alleviated through the mixed method evaluation of horticultural therapy, the method turned out to be effective in relieving anxiety and stress of the subjects and in promoting mental health and sense of achievement. Moreover, Alipour et al. (2020) determined the relevance between the QOL and horticultural therapy due to aging, and reported that horticultural therapy is a noninvasive method that is useful in promoting the quality of elderly life. Other studies are also reporting that horticultural therapy reduces psychological pain by relieving depression that is one of the major mental and behavioral disorders, as well as anxiety, stress and negative emotions (Clatworthy et al., 2013; Gonzalez et al., 2011; Kamioka et al., 2014; Soga et al., 2017).

As such, many studies are pointing out that horticultural therapy is an effective intervention for improving symptoms of subjects suffering from psychological and emotional problems. However, there is insufficient research that applied horticultural therapy to dementia caregivers and examined the effects. Accordingly, this study verified the depression experienced by dementia caregivers as they care for dementia patients and how it affects caregiver burden and QOL, and conducted an exploratory research to determine the applicability of the horticultural therapy program for dementia caregivers.

\section{Research Methods}

\section{Participant recruitment and research}

\section{Participant recruitment}

The purpose of this study and experimental design are approved by the Institutional Review Board of G University (Approval No.: GIRB-A19-Y-0056). The announcement for participant recruitment was posted on the bulletin board of a health center in $\mathrm{H}$ county, and participants were recruited from August 9 to September 1, 2019 at the health center located in H county, Gyeongsangnam-do. The participants were caregivers taking care of the elderly with de- 
mentia who can participate in both pretest and posttest surveys and are willing to participate in eight sessions of the program. The researchers verbally explained to the selected participants about the purpose and process of research as well as participant guidelines during the pretest according to the bioethical regulations, and the research was conducted after obtaining consent for participation. 30 ultimately selected participants were randomly sampled and divided into two groups, 15 in the control group and 15 in the experimental group, and the experiment was conducted in a pretest-posttest quasi-experimental design. The same program was provided for the control group as a reward for participation after the experimental group was done with the entire program.

\section{Implementation of the horticultural therapy program}

The horticultural therapy program was carried out twice a week from September 2 to 25,2019 in total eight sessions. The purpose of the program was to alleviate depression and caregiver burden and improve QOL for caregivers of the elderly with dementia. Detailed goals were to understand dementia, establish a positive self-image, relieve stress, and rebuild family relations and relationship with the person with dementia. These goals were set up with reference to those applied in psychoeducation, counseling and psychotherapy, and mindfulness-based psychotherapeutic intervention programs that have been used to solve psychological and emotional problems of caregivers of the elderly with dementia. According to the findings from other intervention programs, the programs that have the goals to understand dementia, establish a positive self-image, determine the cause of stress faced in the caregiving process and learn how to resolve this, and find the meaning of family relations or relationship with the person with dementia are helpful in alleviating depression and caregiver burden and improving the QOL for caregivers of the elderly with dementia (Cheng et al., 2019; Cheong et al., 2020; J.Y. Kim et al., 2016; Kuo et al., 2016; Livingston et al., 2013; Seo et al., 2018; Yang et al., 2019; Waelde et al., 2017). Based on the purpose of such programs, the program used in this study was organized with consultation of one professor of horticultural therapy, one professor of psychiatry, one professor of social welfare, and one $\mathrm{PhD}$ candidate in horticultural therapy (Table 1). The program was carried out in two steps, personal crisis intervention (Sessions 1-5) and interpersonal crisis intervention (Sessions 6-8), as suggested by Livingston et al. (2013), Kuo et al. (2016), and Yang et al. (2019) to solve the major problems faced by caregivers caring for dementia patients. Moreover, a series of activities were formed by comparing them to the process of plant cultivation, such as 'Garden Formation (Session 1)' $\rightarrow$ 'Sowing (Session 2)' $\rightarrow$ 'Growth (Session 3)' $\rightarrow$ 'Flowering (Sessions 4-5)' $\rightarrow$ 'Fruition and Harvest (Sessions 6-8)'.

More specifically, Session 1 'Garden Formation' was 'Making a dish garden using moss' with the topic 'Empathic garden called dementia'. Session 1 is the introductory step in which the participants brainstormed about dementia, which is a shared topic of conversation for them, with keywords such as 'what comes across the mind regarding dementia' and 'hardships from caring for dementia patients'. The process of forming consensus and rapport about dementia with the participants by sharing one another's thoughts was reinterpreted in terms of 'Forming an empathic garden'. After that, the participants wrapped up by expressing a moss garden as their own rest area to relieve stress from caregiving in the dish garden.

Session 2 'Sowing' had the topic "A flower called 'I", comprised of activities with detailed goals of improving positive self-esteem of individuals and future-oriented thinking through 'Sowing garden nasturtium seeds' in which the participants wrote down their wishes on flower pots and sow seeds and 'Making a name tag using a pressed flower' in which they introduce themselves using adjectives that express their strengths like the plant name tags in the garden. All the attention of caregivers of the elderly with dementia is focused on the dementia patients, which makes them spend most of their personal time caring for the patients, face difficulties in leisure or social activities, and even give up on their everyday life. In the process, the increased caregiver burden causes them to lose their individuality and, in extreme cases, even leads to suicidal ideation or attempt (J.Y. Kim et al., 2016). As such, to resolve the issue of losing oneself due to caregiver burden, the participants sowed seeds while thinking of them as their 
Table 1. Protocols for horticultural therapy program sessions

\begin{tabular}{|c|c|c|c|c|c|}
\hline Session & Step & Topic & Activity & Related plant materials & Goal \\
\hline 1 & \multirow{9}{*}{$\begin{array}{l}\text { Personal } \\
\text { crisis } \\
\text { intervention }\end{array}$} & $\begin{array}{l}\text { Empathic } \\
\text { garden called } \\
\text { 'Dementia' }\end{array}$ & $\begin{array}{l}\text { - Making a dish garden } \\
\text { using a moss }\end{array}$ & $\begin{array}{l}\cdot \text { Leucobryum glaucum } \\
\cdot \text { Rhacomitrium canescens }\end{array}$ & $\begin{array}{l}\text { - Concensus and rapport } \\
\text { formation about dementia } \\
\text { - To express the moss garden as } \\
\text { your own resting place }\end{array}$ \\
\hline \multirow{2}{*}{2} & & \multirow{2}{*}{$\begin{array}{l}\text { A flower } \\
\text { called 'I' }\end{array}$} & $\begin{array}{l}\text { - Making a name tag } \\
\text { using pressed flowers }\end{array}$ & - Various pressed flowers & \multirow{2}{*}{$\begin{array}{l}\text { To improve positive self-esteem } \\
\text { of individuals and } \\
\text { future-oriented thinking }\end{array}$} \\
\hline & & & $\begin{array}{l}\text { - Sowing flower seeds } \\
\text { in flowerpots }\end{array}$ & - Tropaeolum majus & \\
\hline 3 & & $\begin{array}{l}\text { Until the } \\
\text { flower called } \\
\text { 'I' blooms }\end{array}$ & - Making a terrarium & $\begin{array}{l}\cdot \text { Nephrolepis exaltata } \\
\text { "Bostoniensis" } \\
\cdot \text { Davallia mariesii } \\
\text { - Leucobryum glaucum }\end{array}$ & $\begin{array}{l}\text { Objectively express and look at } \\
\text { yourself through the terrarium }\end{array}$ \\
\hline \multirow{2}{*}{4} & & \multirow{2}{*}{$\begin{array}{l}\text { Bursting into } \\
\text { full bloom }\end{array}$} & $\begin{array}{l}\text { - Making a } \\
\text { scandiamoss tree }\end{array}$ & - Cladonia stellaris & \multirow{2}{*}{$\begin{array}{l}\text { To shape and view one's most } \\
\text { positive memory through the } \\
\text { scandiamoss tree }\end{array}$} \\
\hline & & & · Making scented soap & $\begin{array}{l}\cdot \text { Citrus } \times \text { paradisi } \\
\cdot \text { Aniba rosaeodora }\end{array}$ & \\
\hline \multirow{3}{*}{5} & & \multirow{3}{*}{$\begin{array}{c}\text { My } \\
\text { own scent }\end{array}$} & - Making perfume & \multirow{3}{*}{$\begin{array}{l}\text { - Lavandula angustifolia } \\
\cdot \text { Citrus limon } \\
\text { - Rosmarinus officinalis } \\
\text { - Citrus aurantium var. amara } \\
\text { - Rosa Damascena } \\
\text { - Simmondsia chinensis }\end{array}$} & \multirow{3}{*}{$\begin{array}{l}\text { Facing stress and learning how } \\
\text { to manage }\end{array}$} \\
\hline & & & & & \\
\hline & & & $\begin{array}{l}\text { - Making natural skin } \\
\text { toner }\end{array}$ & & \\
\hline 6 & \multirow{5}{*}{$\begin{array}{l}\text { Interpersonal } \\
\text { crisis } \\
\text { intervention }\end{array}$} & $\begin{array}{l}\text { Separate yet } \\
\text { together }\end{array}$ & - Making a herbarium & $\begin{array}{l}\text { Various kinds of preserved } \\
\text { flowers and dry flowers }\end{array}$ & $\begin{array}{l}\text { To refine the relationship and } \\
\text { meaning of each member of the } \\
\text { family by expressing the image } \\
\text { of the family in a harbarium }\end{array}$ \\
\hline 7 & & $\begin{array}{c}\text { My } \\
\text { companion }\end{array}$ & - Making a wreath & $\begin{array}{l}\cdot \text { Cornus walteri } \\
\cdot \text { Tillandsia usneoides } \\
\cdot \text { Tillandsia ionantha }\end{array}$ & $\begin{array}{l}\text { - Facing conflicts with the elderly } \\
\text { with dementia and reorganizing } \\
\text { relationships }\end{array}$ \\
\hline & & \multirow[b]{3}{*}{$\begin{array}{l}\text { Bearing } \\
\text { fruit }\end{array}$} & - Making a yearbook & - Various pressed flowers & \multirow[b]{3}{*}{$\begin{array}{l}\text { - Termination of program } \\
\text { - Improving social support } \\
\text { relationships of self-help groups }\end{array}$} \\
\hline & & & & - Lavandula angustifolia & \\
\hline 8 & & & $\begin{array}{l}\text { - Making and giving } \\
\text { herbal tea bags }\end{array}$ & $\begin{array}{l}\cdot \text { Rosmarinus officinalis } \\
\cdot \text { - Jasminum grandiflorum } \\
\cdot \text { - Mentha } \times \text { piperita } \\
\cdot \text { - Chamaemelum nobile } \\
\cdot \text { - Rosa rubiginosa } \\
\cdot \text { - Melissa officinalis } \\
\text { - Aspalathus linearis }\end{array}$ & \\
\hline
\end{tabular}

wishes in Session 2, determined their strengths and introduced them, through which they could form positive future-oriented thinking and sense of self.

In Session 3 'Growth', the participants made terrariums with the topic "Until the flower called 'I' blooms". A terrarium is to create a cyclical ecosystem by putting soil and plants inside a container. In this session, the participants were to associate the positive aspects of their attributes (individual character, memories, etc.) with various materials put into the terrarium in the process of embodying the terrarium into themselves. They used various colors of sand for soil that lay the groundwork for plants to live, thereby expressing their personalities or memories related to each color. For plants, they looked at the plants and tried to find the resemblance to them and express the planted plant as themselves. This process enabled them to explore what 
they are made of to the point of what they are today and objectively express and see themselves through the terrarium.

Sessions 4 and 5 'Flowering' were carried out with the topic of flowers and scents. Moreover, in each session, activities to improve self-esteem were carried out as a wrap-up of personal crisis intervention, such as having the participants made and give a present for themselves as they have lost themselves by focusing only on dementia patients in the caregiving process. Session 4, with the topic 'Bursting into full bloom', encouraged the participants to think of an image of flowers in full bloom, having them talk about their memories of full-blown flowers and going outside to enjoy flowers in spring. They associated the full-blown flowers with the golden days of their lives, and brainstormed on the keyword 'Spring of my life'. After that, they compared scandia moss with cherry blossoms, created a model of full-blown cherry tree and visually embodied their personal image of 'Spring of my life'. Moreover, for making a gift for oneself, there was 'Making scented soap' in which the participants mixed materials that are right for their skin type and mold them into any shape they want. These activities were to help them recall their most positive memories, objectify and view them, thereby forming a positive self-image that was set as a detailed goal.

In Session 5 related to the scent of flowers, the participants were to make a gift for themselves with the topic 'My own scent' and carried out 'Making aromatic roll-on perfume' and 'Making natural skin toner'. According to J.Y. Kim et al. (2016), there must be counseling and programs to promote mental health including immediate intervention and post management of caregiver burden and stress to manage personal crises such as suicide of caregivers of the elderly with dementia. Accordingly, the detailed goal of Session 5 is to learn how to face and manage stress, as the last step of personal crisis intervention. To achieve this goal, the participants faced their individual stress through brainstorming of their current stress, the situation in which they are stressed, and how they each relieve their stress with the keyword 'stress'. Then they were to smell the aroma of lavender, grapefruit and rose wood essential oil that are known to help relieve stress by calming the nerves (Bikmoradi et al., 2015; de Almeida et al., 2009; Tanida et al., 2005). After that they shared how they feel about each scent, and made roll-on perfume by mixing essential oils. Then, with the method of using roll-on perfume they had made, they were encouraged to perceive stress when they face a stressful situation and conduct behavior that can alleviate stress (acupressure using roll-on perfume), teaching them the cognitive behavioral method to relieve stress in a different way. After that, in the activity of making a gift for oneself, the participants chose natural ingredients that are suitable for individual skin type and made skin toner. A gift presentation ceremony was held, in which the therapist complimented the participants on their individual efforts to care for the elderly with dementia and presented the gifts. This aromatic roll-on perfume and natural skin toner making process was intended to make individuals face their stress, learn how to manage it and improve self-esteem.

Sessions 6-8 are the conclusion part of the program with the meaning of 'Fruition and Harvest'. Moreover, these sessions are the interpersonal crisis intervention step, in which detailed goals were established to resolve issues mentioned in studies on caregivers of the elderly with dementia (J.Y. Kim et al., 2016; Kuo et al., 2016; Livingston et al., 2013; Seo et al., 2018; Yang et al., 2019), such as interpersonal problems in caregiving like deterioration of family relations, dysfunctional communication with the elderly with dementia, and frustrations about social life and relationships.

In Session 6 'Separate yet together', the participants carried out activities on family relations. If there is an elder with dementia within the family, the family experiences change in the new family system among the members due to the matter of caregiving for the elderly with dementia. Here, if the family relations face a negative change, this leads to family conflicts that result in decreased psychological and emotional support resources of caregivers and interpersonal problems, which add to the caregiver burden. On the other hand, suitable changes in the family system operate the support function of the family, which brings positive effects that not only solve interpersonal problems but also reduce the caregiver burden (Seo et al., 2018). Therefore, interventions for caregivers of the elderly with dementia often deal with resolution of dysfunctional family relations. Accordingly, the 'Herbarium making' activity was carried out with the detailed goal of reestablishing the 
meaning of family relations destroyed in the process of caring for the elderly with dementia. In the introductory step, the participants drew a family tree to examine their relationship with each family member, and explored the meaning of family in this process. Then, in the development step, they compared the family members to various plant materials such as dried and preserved flowers prepared, and filled the herbarium container with these materials, expressing the image of family from the view of caregivers caring for the elderly with dementia in the herbarium. This process helped the participants reestablish the meaning of relationship with each family member.

In Session 7 'My companion', the participants faced the conflicts with the elderly with dementia and participated in 'Making a wreath' with the detailed goal of reorganizing relationships. Caregivers taking care of the elderly with dementia sometimes take a dysfunctional measure such as avoiding their problems as a coping strategy in their relationship with the dementia patient. This avoidance-focused coping strategy develops burnout and negative emotions of caregivers, whereas the task-focused coping strategy that helps the caregivers actively face, explore and improve such relationship is known to reduce negative emotions and caregiver burden (Iavarone et al., 2014). Therefore, interventions for caregivers require activities that face the relationship with the dementia patient. Accordingly, this activity helped the participants compare each stem of Cornus walteri with their good and bad memories of their relationship with the patient, through which they could face the relationship building between the participant and the elderly with dementia. Later, to turn the negative aspects into positive aspects of their relationship with the elderly with dementia, the participants decorated the wreath frame made of Cornus walteri with tillandsia that is mentioned as an air purifying plant by the media (Rural Development Administration, 2016; Yun, 2018), thereby making a dreamcatcher that has the meaning of giving sweet dreams by controlling nightmares (Dreamcatcher, n.d.). The participants face their relationship with the dementia patients through the process of making a wreath, and eliminated their negative relationships in the process of giving meaning to the wreath with objects (tillandsia and dreamcatcher) that reduce negative things like particulate matter or night- mares, thereby switching the meaning of relationships into a positive direction.

Finally, in Session 8 'Bearing fruit', the participants carried out activities such as 'Making a yearbook' and 'Making and giving herbal tea bags' with the detailed goals of ending the program and improving social support of self-help groups. To begin with, the participants made a yearbook using photos from their activities and pressed flowers as they reflect on the activities in the last seven sessions. Then they sampled various herbal teas and mixed the ones they prefer to create their own herbal tea bags. They exchanged them as gifts with other participants and ended the program. Caregivers of the elderly with dementia tend to experience social activity constraints due to caregiving and interpersonal problems, and dementia family programs are carried out to solve these problems. Dementia family programs promote cognitive information about dementia, improve coping skills, and resolve psychological and interpersonal issues such as caregiver burden, depression and stress by providing psychoeducation, counseling or self-help groups. The self-help groups formed in such programs help caregivers solve interpersonal problems and increase voluntary support capacity by building a social network based on bonds among the caregivers (Park and Park, 2015; Seo et al., 2018). Therefore, the ending of this program is not an ending of all relationships but formation of self-help groups, reflecting on the activities they have done together and improving social support and relationships in the process of exchanging gifts they made themselves.

The program was carried out by one main host (Korean Horticultural Therapy and Well-being Association Horticultural Therapist Registered-Grade 2) and one assistant. Each session was from 90 to 120 minutes including 10 minutes of break time, and the program was carried out in the multipurpose program room in the health center of Haman-gun.

\section{Survey and analysis method}

\section{Assessment tool}

For survey items, this study collected demographic characteristics such as gender, age, and period of providing care for the elderly with dementia, using scales such as depression, life quality and caregiver burden of caring for 
the elderly with dementia through the horticultural therapy program.

\section{(1) Depression}

The Korean version of the Center for Epidemiologic Studies-Depression Scale (CES-D), which is frequently used to measure depressive symptoms of the general public, is used in this study, which is structured as a result of factor structuring of Bae and Shin (2005) into depressive emotions (seven items), positive emotions (four items), slowing of physical behavior (seven items), and interpersonal relations (two items). According to Bae and Shin (2005), the scale had a high reliability with the internal consistency of .927 , and in this study Cronbach's $\alpha$ was .872. The items were to record the frequency of emotions felt in the past week, and thus the participants checked off their responses ranging from 'Seldom (less than 1 day) = 0 point', 'Occasionally (1-2 days) $=1$ point', 'Frequently $(3-4$ days $)=2$ points', and 'Almost always (5-7 days) $=$ 3 points' and calculated their scores, while reverse scoring positive emotions. The range of total scores is 0-60 points, with 0-9 points indicating 'not depressed', 10-21 points 'borderline depression', and 22-60 points 'has depressive symptoms'.

(2) Quality of life

The QOL scale used in this study was WHO QOL-BREF (WHOQOL-BREF) adapted and developed from the short version by the WHO into Korean (Min et al., 2000). The reliability of the scale when developed was .898, showing high internal consistency, and Cronbach's $\alpha$ in this study was .925 , also showing high internal consistency. The survey is comprised of 26 items measuring general QOL and health (two items), physical health (seven items), psychological aspects (six items), social relations (three items), and environmental aspects (eight items). The items are rated on a 5-point Likert scale, with higher scores indicating higher QOL.

\section{(3) Caregiver burden}

The caregiver burden scale used in this study was the caregiver burden scale for dementia family developed by Kwon (1996). This study is comprised of 28 items rated on a 5-point Likert scale. Sub-items are comprised of social activity constraints social activity constraints (six items), negative change in the elderly-primary caregiver relationship (seven items), deterioration of family relations (five items), psychological burden (four items), burden in terms of finance and economic activities (three items), and change in health (three items). The reliability of the scale when developed was .908, showing high internal consistency, and Cronbach's $\alpha$ in this study was .936, also showing a high level of internal consistency.

\section{Analysis method}

To analyze the results after the horticultural therapy program, this study excluded the participants that did not participate in all sessions of the program or did not conduct the posttest. Accordingly, the analysis was conducted using pretest-posttest data of 19 participants (10 in the experimental group, nine in the control group) out of 30 participants that were initially recruited. The analysis was conducted using IBM SPSS Statistics 25.0 Program. As a result of conducting the Shapiro-Wilk test of normality for the pretest results to determine the data analysis method, all items did not have normality. Accordingly, along with basic descriptive statistics, the pretest-posttest between-group difference through the Mann-Whitney $U$ test as a non-parametric method and the pretest-posttest within-group difference through the Wilcoxon signed rank test were tested at the $95 \%$ significance level.

\section{Results and Discussion}

\section{Participant characteristics and preliminary test of homogeneity}

\section{Participant characteristics}

All the participants were female, and their average age was 58.78 in the experimental group ( $\mathrm{SD}=9.56)$, and 61.3 in the control group ( $\mathrm{SD}=12.40$ ). The average caregiving period of the participants was 6.00 years in the experimental group $(\mathrm{SD}=3.12)$, and 4.00 years in the control group ( $\mathrm{SD}=2.40)$. Moreover, there was no statistically significant difference found as a result of conducting a stat- 
istical analysis to test the homogeneity on the average age and average caregiving period of the experimental group and control group.

\section{Preliminary test of homogeneity on survey items}

Table 2 shows the result of conducting the preliminary test of homogeneity on scores of depression, QOL and caregiver burden. The analysis result showed that there is no significant difference between groups. Accordingly, the two groups are homogeneous in terms of depression, QOL and caregiver burden.

\section{Changes after the horticultural therapy program}

\section{Depression}

We tested the posttest mean difference of depression between the groups after the horticultural therapy program and analyzed the pretest-posttest mean by group (Table 3). As a result of testing the posttest mean difference between the groups, there was no significant difference between the groups in the total score of depression and detailed items.

In the control group, the detailed items increased in the posttest, even though they were not statistically significant: depressive emotions increased from $10.33(\mathrm{SD}=3.54)$ to 12.22 ( $\mathrm{SD}=3.83)$, positive emotions (reverse scoring) from $9.78(\mathrm{SD}=1.20)$ to $9.89(\mathrm{SD}=1.54)$, physical inactivity from $10.33(\mathrm{SD}=2.65)$ to $11.78(\mathrm{SD}=1.86)$, and interpersonal relationship from $2.56(\mathrm{SD}=0.88)$ to $2.78(\mathrm{SD}=0.83)$ after the program. Accordingly, the total score of depression increased from $33.00(\mathrm{SD}=7.26)$ to 36.67 ( $\mathrm{SD}=6.95)$. As such, depression increased overall in the control group after the program, although not at a significant level.

On the other hand, the comparison of the pretest-posttest scores of the experimental group showed that the detailed items decreased in the pretest: depressive emotions from $13.50(\mathrm{SD}=5.56)$ to $13.10(\mathrm{SD}=4.89)$, positive emotions (reverse scoring) from $8.50(\mathrm{SD}=2.42)$ to $7.90(\mathrm{SD}=$ 2.33), physical inactivity from $12.90(\mathrm{SD}=2.92)$ to 11.80 $(\mathrm{SD}=3.33)$, and interpersonal relationship from 3.60 $(\mathrm{SD}=1.96)$ to $3.10(\mathrm{SD}=1.91)$ after the program. Accordingly, the total score of depression decreased from $38.50(\mathrm{SD}=11.756)$ to $35.90(\mathrm{SD}=11.80)$. As such, the total score of depression and detailed items decreased overall in the experimental group after the program, although not at a statistically significant level.

Table 2. Homogeneity test of subject's characteristics

\begin{tabular}{|c|c|c|c|c|c|}
\hline \multirow{2}{*}{ Variable } & \multicolumn{2}{|c|}{ Control group $(n=9)$} & \multicolumn{2}{|c|}{ Experimental group $(n=10)$} & \multirow{2}{*}{$p$} \\
\hline & M & SD & M & SD & \\
\hline Depression & 33.00 & 7.26 & 38.50 & 11.75 & $.278^{\mathrm{NS}}$ \\
\hline Quality of life & 65.33 & 9.23 & 61.59 & 12.98 & $.661^{\mathrm{NS}}$ \\
\hline Caregiver burden & 90.44 & 19.30 & 88.30 & 13.47 & $.905^{\mathrm{NS}}$ \\
\hline
\end{tabular}

${ }^{\mathrm{NS}}$ Non-significant by Mann-Whitney U test.

Table 3. Effects of a horticultural therapy program on depression

\begin{tabular}{|c|c|c|c|c|c|c|c|}
\hline \multirow{2}{*}{ Variables } & \multicolumn{3}{|c|}{ Control group $(n=9)$} & \multicolumn{3}{|c|}{ Experimental group $(\mathrm{n}=10)$} & \multirow{2}{*}{$p^{\mathrm{z}}$} \\
\hline & Pre & Post & $p^{\mathrm{y}}$ & Pre & Post & $p^{\mathrm{y}}$ & \\
\hline Depressive emotions & $10.33(3.54)$ & $12.22(3.83)$ & .160 & $13.50(5.56)$ & $13.10(4.89)$ & .473 & .730 \\
\hline Positive emotions & $9.78(1.20)$ & $9.89(1.54)$ & .596 & $8.50(2.42)$ & $7.90(2.33)$ & .167 & .113 \\
\hline Physical inactivity & $10.33(2.65)$ & $11.78(1.86)$ & .159 & $12.90(2.92)$ & $11.80(3.33)$ & .153 & .780 \\
\hline Interpersonal relationship & $2.56(0.88)$ & $2.78(0.83)$ & .414 & $3.60(1.96)$ & $3.10(1.91)$ & .236 & .842 \\
\hline Total depression & $33.00(7.26)$ & $36.67(6.95)$ & .109 & $38.50(11.75)$ & $35.90(11.80)$ & .123 & .481 \\
\hline
\end{tabular}

Note. Values are mean(standard deviation). Reverse scored items were used for positive emotions.

${ }^{\mathrm{z}}$ Post-Post $p$-value by Mann-Whitney U test.

${ }^{\mathrm{y}}$ Pre-Post $p$-value by Wilcoxon signed rank test. 
Depression is a common psychological and emotional problem of caregivers caring for patients and suffering from caregiver burden, and this is especially more severe among caregivers of the elderly with dementia than other caregivers (Givens et al., 2014; Hernandez and Bigatti, 2010; Kuo et al., 2016). Depression suffered by dementia caregivers increase due to the behavioral and psychological symptoms and problems that come from the cognitive and behavior disorders of dementia patients (Givens et al., 2014). Accordingly, psychotherapeutic interventions for dementia caregivers are focused on social support as well as understanding the behavioral problems of dementia patients, learning how to manage them, and improving the individual competencies of caregivers (Kuo et al., 2016; Livingston et al., 2013; Yang et al., 2019).

Horticultural therapy is proved by many studies to be effective in improving depressive symptoms of various subjects. Gonzalez et al. (2010) implemented a horticultural therapy program on patients clinically showing depressive symptoms and discovered that nature-based horticultural activities bring fascination toward nature, helping them psychologically break free from the struggles in daily life, restore attention and improve clinical depressive symptoms. Gonzalez et al. (2011) also proved that the horticultural therapy program alleviates depression, anxiety, stress and negative emotions of adults diagnosed with depression and improves positive emotions, thereby reducing psychological pain. Moreover, according to literature reviews on horticultural therapy performed on subjects with mental and behavior disorders or problematic symptoms, horticultural therapy had positive effects on depression, which is one of the major symptoms of mental and behavior disorders (Clatworthy et al., 2013; Kamioka et al., 2014; Soga et al., 2017).

Unlike the results of previous studies in which horticultural therapy is found effective in alleviating depressive symptoms, this study did not show a significant level of positive change as a result of the statistical testing. This may be firstly due to the fact that the number of subjects is not big enough to test the effects of horticultural therapy. A non-parametric test was conducted to make up for this deficiency, but the problem is that statistical significance is dependent on sample size (Wasserstein and Lazar, 2016).
The result of this study showed that, although not statistically significant, the control group showed an increase in scores overall, while the experimental group showed a decrease. This implies that different results may be expected when more subjects are recruited in further research. The second reason may be the fact that the program was carried out in a short period of time. The total scores of depression before the program showed that both the experimental group $(\mathrm{M}=38.50, \mathrm{SD}=11.75)$ and control group $(\mathrm{M}=33.00, \mathrm{SD}=7.26)$ showed high depression in the range of 'Has depressive symptoms (22-60 points)'. According to Son et al. (2006), long intervention periods are effective if the purpose is mental and psychological rehabilitation, and Kim et al. (2020) also mentioned that it was effective to apply at least 3-4 months of the program aimed at mental and psychological rehabilitation. However, this study was conducted in a relatively short period of time, twice a week for 4 weeks (about a month), which is not enough time alleviate the high level of depression among the participants. However, the tendency of change in the depression scores between the groups showed that the depression scores increased in the control group whereas they decreased in the experimental group. This implies that different results may be expected when the program is implemented for a longer period of time in additional research.

As a result of implementing the horticultural therapy on dementia caregivers, the depression scores were decreasing overall, although not at a statistically significant level. Considering the effect of horticultural therapy in improving depressive symptoms as reported by many previous studies, the activities in the program enabled the participants to understand more about dementia, obtain social support by communicating with other dementia caregivers, and secure a positive self-image, which had effects on relieving their depressive emotions, establishing positive emotions, improving symptoms of slowing physical behaviors, and releasing the need for interpersonal relations, thereby alleviating depressive symptoms. Accordingly, this proved the applicability of the horticultural therapy program as an intervention for alleviating depressive symptoms of dementia caregivers. Further research is suggested to make up for the deficiency of sample size, which is the limitation of 
this study, and then test the additional issue of intervention period.

\section{Quality of life}

We tested the posttest mean difference of QOL between the groups after the horticultural therapy program and conducted the pretest-posttest mean analysis by group (Table 4). The result of testing the posttest mean difference between the groups showed that there was no statistically significant difference in the total score of QOL and all detailed items.

As for the pretest-posttest mean analysis by group in the control group, there was no statistically significant difference found overall. On the other hand, in the experimental group, general QOL and general health increased from $11.60(\mathrm{SD}=3.75)$ to $14.20(\mathrm{SD}=2.90)$ at a significant level $(p=.020)$, and physical health increased from 13.09 $(\mathrm{SD}=1.80)$ to $14.17(\mathrm{SD}=2.31)$ at a nearly significant level $(p=.057)$. Psychological health, social relations and environment also increased from $11.87(\mathrm{SD}=2.84)$ to $13.80(\mathrm{SD}=2.65), 12.53(\mathrm{SD}=2.44)$ to $12.93(\mathrm{SD}=1.55)$, and $12.50(\mathrm{SD}=3.47)$ to $13.75(\mathrm{SD}=2.90)$, respectively, but not at a statistically significant level. Moreover, as for the total score of QOL, the control group showed a decrease from $65.33(\mathrm{SD}=9.23)$ to $64.16(\mathrm{SD}=9.20)$, although not at a statistically significant level, whereas the experimental group showed an increase from $61.59(\mathrm{SD}=12.98)$ to $68.85(\mathrm{SD}=9.83)$ at a nearly significant level $(p=.059)$.

Caregivers of the elderly with dementia face severe stress and constraints on daily life due to behavioral and psychological problems and difficulty in performing daily activities due to the cognitive impairment of the dementia patient, and their QOL decreases as a result (D'Onofrio et al., 2015; Kim, 2017). Therefore, Yang et al. (2019) claimed the need for occupational therapy intervention programs to maintain and improve the QOL for caregivers of the elderly with dementia.

Horticultural therapy is also one of occupational therapy interventions, and many studies are conducted to maintain and improve the QOL for various subjects. Oh et al. (2012) discovered that the horticultural therapy program for women that survived cancer was effective in reducing state anxiety and improving QOL. Sommerfeld et al. (2010) claimed that horticultural activities carried out as for recreation satisfied the desire for creation upon encountering nature and formed a healthy lifestyle, improved the QOL and health, and thus showed effect in increasing the elderly's physical activities and QOL. Perrins-Margalis et al. (2000) applied horticultural therapy as a group activity for patients with chronic mental illness, and reported that it had an immediate positive effect on QOL such as life satisfaction, well-being and self-concept.

As such, many studies are proving that horticultural therapy is effective in improving QOL, and this study also showed that it had positive effects on promoting QOL for dementia caregivers. In terms of personal crisis intervention and interpersonal crisis intervention in each step of the program, the participants could interact with others and pro-

Table 4. Effects of a horticultural therapy program on quality of life

\begin{tabular}{|c|c|c|c|c|c|c|c|}
\hline \multirow{2}{*}{ Variable } & \multicolumn{3}{|c|}{ Control group $(n=9)$} & \multicolumn{3}{|c|}{ Experimental group $(n=10)$} & \multirow{2}{*}{$p^{\mathrm{z}}$} \\
\hline & Pre & Post & $p^{\mathrm{y}}$ & Pre & Post & $p^{\mathrm{y}}$ & \\
\hline General overall QOL and general health & $11.78(3.07)$ & $12.67(2.64)$ & .496 & $11.60(3.75)$ & $14.20(2.90)$ & $.020^{*}$ & .356 \\
\hline Physical health & $14.03(2.20)$ & $12.57(2.42)$ & .326 & $13.09(1.80)$ & $14.17(2.31)$ & .057 & .156 \\
\hline Psychological health & $13.18(1.36)$ & $13.55(2.26)$ & .725 & $11.87(2.84)$ & $13.80(2.65)$ & .106 & .720 \\
\hline Social relation & $12.44(2.83)$ & $11.48(2.74)$ & .340 & $12.53(2.44)$ & $12.93(1.55)$ & .734 & .182 \\
\hline Environmental & $13.89(1.22)$ & $13.89(1.39)$ & .629 & $12.50(3.47)$ & $13.75(2.90)$ & .120 & .842 \\
\hline Total QOL score & $65.33(9.23)$ & $64.16(9.20)$ & .496 & $61.59(12.98)$ & $68.85(9.83)$ & .059 & .278 \\
\hline
\end{tabular}

Note. Values are mean(standard deviation). QOL $=$ Quality of life.

${ }^{\mathrm{z}}$ Post-Post $p$-value by Mann-Whitney U test.

${ }^{\mathrm{y}}$ Pre-Post $p$-value by Wilcoxon signed rank test.

${ }^{*} p<.05$. 
mote understanding about themselves in mutually dynamic connections with nature mediated by horticulture so that they can establish a positive self-image and rebuild interpersonal relations, thereby achieving self-growth and improving QOL. Furthermore, the process of horticultural activities increased physical activity and promoted physical health, and decorating the surroundings with outputs they had made themselves during the activities improved their living environment, thereby promoting QOL. In particular, the aforementioned effect of the intervention applied in this study is supported by Töpfer and Wilz (2020), who reported that the psychological intervention program for dementia caregivers improves positive experience based on the strengths of the subjects with cognitive-behavioral methods and teaches how to cope with negative experience, which serves as a potential mechanism for improving QOL.

\section{Caregiver burden}

We tested the posttest mean difference of caregiver burden between the groups after the horticultural therapy program and conducted the pretest-posttest mean analysis by group (Table 5). The result of testing the posttest mean difference between the groups showed that there was a statistically significant difference only in the score of social activity constraints, which is a detailed item of caregiver burden $(p<.001)$.

As for the pretest-posttest mean analysis by group in the control group, there was no statistically significant difference found in the total score as well as detailed items other than social activity constraints. Social activity constraints showed a significant increase from $18.44(\mathrm{SD}=6.21)$ to 23.11 ( $\mathrm{SD}=2.80 ; p=.050$ ). This increased burden of social activity constraints some time after the pretest is explained by the fact that personal time of caregivers decreases in the process of caring for dementia patients, which reduces their time for leisure and social activities and limits social activities, thereby decreasing their satisfaction with interpersonal relations after some time (Chenoweth and Spencer, 1986; Deimling and Bass, 1986; H.J. Kim et al., 2016).

On the other hand, in the experimental group, the total score of caregiver burden decreased from $88.30(\mathrm{SD}=13.47)$ to $82.50(\mathrm{SD}=12.16)$, and in the detailed item pretest-posttest score change, social activity constraints decreased from $17.50(\mathrm{SD}=3.17)$ to $13.60(\mathrm{SD}=4.43)$ at a significant level $(p=.028)$. This result is similar to that of many studies proving that many subject groups showed social effects of positive change in interpersonal relations, communication and sense of closeness through horticultural therapy (Harris and Trauth, 2020; Hartig et al., 2014; Kim et al., 2019; Song et al., 2015). Such social effects of horticultural therapy appear due to interactions in the dynamic process of horticultural therapy (Relf, 1981). Relf (1981) argued that interactions in terms of therapeutic dynamics cause

Table 5. Effects of a horticultural therapy program on caregiver burden

\begin{tabular}{|c|c|c|c|c|c|c|c|}
\hline \multirow{2}{*}{ Variable } & \multicolumn{3}{|c|}{ Control group $(\mathrm{n}=9)$} & \multicolumn{3}{|c|}{ Experimental group $(\mathrm{n}=10)$} & \multirow{2}{*}{$p^{\mathrm{z}}$} \\
\hline & Pre & Post & $p^{y}$ & Pre & Post & $p^{y}$ & \\
\hline $\begin{array}{l}\text { Negative change in the elderly-caregiver } \\
\text { relationship }\end{array}$ & $27.44(4.67)$ & $26.11(5.16)$ & .279 & $26.60(5.13)$ & $25.70(5.21)$ & .673 & .842 \\
\hline Social activity constraints & $18.44(6.21)$ & $23.11(2.80)$ & $.050^{*}$ & $17.50(3.17)$ & $13.60(4.43)$ & $.028^{*}$ & $<.001^{* * *}$ \\
\hline Negative change in family relationship & $15.67(3.61)$ & $14.22(4.29)$ & .323 & $16.00(5.40)$ & $14.40(6.04)$ & .759 & .842 \\
\hline Psychological burden & $12.67(4.53)$ & $14.22(3.73)$ & .168 & $13.50(3.81)$ & $13.30(3.92)$ & .643 & .497 \\
\hline Financial and job-related burden & $6.67(2.00)$ & $6.44(2.07)$ & .915 & $5.60(0.84)$ & $6.00(2.16)$ & .732 & .780 \\
\hline Health-related burden & $9.56(3.21)$ & $10.33(3.04)$ & .551 & $9.10(1.29)$ & $9.50(2.37)$ & .725 & .243 \\
\hline Total & $90.44(19.30)$ & 94.44(17.39) & .594 & $88.30(13.47)$ & $82.50(12.16)$ & .113 & .079 \\
\hline
\end{tabular}

Note. Values are mean(standard deviation).

${ }^{\mathrm{z}}$ Post-Post $p$-value by Mann-Whitney U test.

${ }^{\mathrm{y}}$ Pre-Post $p$-value by Wilcoxon signed rank test.

${ }^{*} p<.05,{ }^{* * *} p<.001$. 
various social contacts among subjects, between subjects and therapists, and between subjects and the community. In particular, the horticultural therapy program implemented in this study encouraged the participants to build rapport using the common topic of 'dementia' from the beginning of the program, which quickly promoted cohesiveness among the self-help groups and stimulated 'interactions between participants'. Yet, due to the nature of the elderly with dementia, the burden of social activity constraints caused by the constraints on personal life may decrease only by participating in the existing family support program, breaking free from those constraints even for a little while (Seo et al., 2018). However, compared to other general results of this study, the statistically significant difference in the burden of social activity constraints also proved by the posttest analysis results between the groups may be the effect of horticultural therapy that provided interventions using horticultural activities as the medium with reference to applications of existing intervention programs for caregivers of the elderly with dementia. This is because horticultural activities help build smooth relationships with others in a nonverbal way even in terms of interactions among the subjects, thereby providing an ideal environment that encourages them to make social contact without resistance, such as facing the problem of interpersonal relations (Relf, 1981).

Moreover, although not statistically significant, the results also showed decreased scores in the negative change in the elderly-primary caregiver relationship, negative change in family relations, and psychological burden. This result is due to the gender characteristics, as the caregivers of the elderly with dementia are women. According to Iavarone et al. (2014), female caregivers suffer emotion-focused burden and pain as a coping strategy to protect the elderly with dementia, which can be reduced by providing restructuring of the cognitive view of dementia. Due to these characteristics, in the process of talking about their difficulties regarding dementia and obtaining knowledge about dementia in the horticultural therapy program, the participants built rapport and emotionally communed with others, and reestablished the meaning of family relations and relationship with the dementia patient, which restructured the cognitive view and reduced the scores in the emotion-focused burden. This positive change, although not statistically significant, may be due to the small sample size or short period of time previously mentioned as the limitations of this study. Accordingly, further research is suggested to make up for these deficiencies and, as mentioned by Iavarone et al. (2014), test whether the results are due to the difference in coping strategies to protect the elderly with dementia depending on gender as a demographic characteristic.

On the other hand, burden of financial and economic activities and burden of health tended to increase. This is because caregivers faced greater burden in terms of development and physical aspects due to gender characteristics (Iavarone et al., 2014), and also because it becomes more difficult for them to conduct economic activities due to the nature of the disease (J.Y. Kim et al., 2016; Kwon, 2002; Yoo and Kim, 2004). However, the horticultural therapy program in this study was formed to threat psychological and emotional problems of the participants, and thus could not alleviate burden of financial and economic activities. By overcoming the limitations of this study such as the relatively short period of time and limited space of the site where the program was implemented and carrying out various horticultural activities for at least a certain period of time in a place where big movements can be made such as gardening, it would be possible to solve the problems of physical burden through horticultural therapy, considering the results of studies by Sommerfeld et al. (2010) and Park et al. (2014) claiming that horticultural activities such as gardening prevented decline of physical functions due to aging and promoted physical health.

The intensified caregiver burden due to chronic stress of caregivers of the elderly with dementia has negative effects on psychological and physical health of not only the dementia patient but also other family members and caregivers, which is why there is a need for intervention strategies to support them in lessening their burden (Schulz et al., 2020). A meta-analysis proved that non-pharmacological intervention programs for caregivers of the elderly with dementia such as mindfulness-based counseling and psychotherapy were effective in reducing depressive symptoms, stress and caregiver burden of subjects (Cheng et al., 2020). Like the results of non-pharmacological inter- 
vention programs applied as psychotherapy, horticultural therapy also proved its effects in lessening caregiver burden, especially the burden of social activity constraints, of dementia caregivers based on the results of this study. Furthermore, positive results can be found in other categories of caregiver burden by applying a program that overcomes the aforementioned limitations of this study. The results proved the potential of horticultural therapy as an intervention strategy to lessen the caregiver burden of dementia caregivers based on the effects of alleviating the burden of caring for the elderly with dementia.

\section{Conclusion}

This study is conducted to verify the applicability of the horticultural therapy program developed to alleviate depression and caregiver burden and promote QOL of caregivers caring for dementia patients. The participants of this study are primary caregivers that are currently taking care of dementia patients. They were women with a high level of depression looking after dementia patients for an average of 4 years in the control group ( 2 to 10 years) and 6 years in the experimental group ( 2 to 10 years). The program applied to the experimental group was carried out twice a week for 4 weeks in total 8 sessions. Sessions 1-5 were set up as the personal crisis intervention step, and Sessions 6-8 as the interpersonal crisis intervention with reference to psychotherapy programs for dementia caregivers.

The results showed that depression generally increased in the control group in the posttest, although not at a significant level. On the other hand, the total depression score and detailed items generally decreased in the experimental group that received horticultural therapy, although not at a statistically significant level. QOL did not show much change in the posttest in the control group, but general QOL and general health increased significantly in the experimental group, and physical health and the total score of QOL increased almost significantly. Finally, caregiver burden did not show much pretest-posttest change in the control group, whereas social activity constraints and total caregiver burden score decreased significantly in the experimental group.
These results are consistent with those of previous studies that implemented horticultural therapy to solve psychological and emotional problems of the general public, mentally ill patients or the elderly. Accordingly, this study verified the applicability of horticultural therapy to not only the subjects examined in previous studies but also dementia caregivers, by helping reduce their caregiver burden and severe depression and improve QOL. At this point where the aging population and the rapid increase of dementia patients are causing psychological problems such as caregiver burden of dementia caregivers to emerge as social problems, the results of this study verified the accessibility to a new method to support dementia caregivers by proving the applicability of horticultural therapy that implemented the conventional psychotherapy intervention strategies. However, there are limitations in this study that the results cannot be generalized due to the small sample size, selection of female participants only, and limited dependent variables. Accordingly, additional research is suggested to generalize the results of this study. We also suggest developing a manual on the suitable treatment period and number of sessions by systemizing the program and verifying the effects of horticultural therapy on mental health of dementia caregivers by measuring various psychological and emotional factors.

\section{References}

Alipour, F., E.S. Ilali, A. Hesamzadeh, and S.N. Mousavinasab. 2020. The role of horticultural therapy in improving the quality of life in elderly people. J. Mazandaran Univ. Med. Sci. 29(181):82-93.

Bae, S.W. and W.S. Shin. 2005. The factor structure of the CES-D scale (the center for epidemiologic studies-depression scale): An application of confirmatory factor analysis. Health Soc. Sci. 18:165-190.

Bikmoradi, A., Z. Seifi, J. Poorolajal, M. Araghchian, R. Safiaryan, and K. Oshvandi. 2015. Effect of inhalation aromatherapy with lavender essential oil on stress and vital signs in patients undergoing coronary artery bypass surgery: A single-blinded randomized clinical trial. Complement. Ther. Med. 23(3):331-338. https://doi.org/ 
10.1016/j.ctim.2014.12.001

Cheng, S.T. 2017. Dementia caregiver burden: A research update and critical analysis. Curr. Psychiatry Rep. 19(9):64-72. https://doi.org/10.1007/s11920-017-0818-2

Cheng, S.T., A. Au, A. Losada, L.W. Thompson, and D. Gallagher-Thompson. 2019. Psychological interventions for dementia caregivers: What we have achieved, what we have learned. Curr. Psychiatry Rep. 21(7):59-71. https://doi.org/10.1007/s11920-019-1045-9

Cheng, S.T., K.K. Li, A. Losada, F. Zhang, A. Au, L.W. Thompson, and D. Gallagher-Thompson. 2020. The effectiveness of nonpharmacological interventions for informal dementia caregivers: An updated systematic review and meta-analysis. Psychol. Aging 35(1):55-77. https://doi.org/10.1037/pag0000401

Chenoweth, B. and B. Spencer. 1986. Dementia: The experience of family caregivers. Gerontologist 26(3):267-272. https://doi.org/10.1093/geront/26.3.267

Clatworthy, J., J. Hinds, and P.M. Camic. 2013. Gardening as a mental health intervention: A review. Ment. Health Rev. J. 18(4):214-225. https://doi.org/10.1108/MHRJ-02 $-2013-0007$

de Almeida, R.N., D.A. Araújo, J.C. Gonçalves, F.C. Montenegro, D.P. de Sousa, J.R. Leite, R. Mattei, M.A. Benedito, J.G. de Carvalho, J.S. Cruz, and J.G. Maia. 2009. Rosewood oil induces sedation and inhibits compound action potential in rodents. J. Ethnopharmacol. 124(3):440-443. https://doi.org/10.1016/j.jep.2009.05.044

Deimling, G.T. and D.M. Bass. 1986. Symptoms of mental impairment among elderly adults and their effects on family caregivers. J. Gerontol. 41(6):778-784. https://do i.org/10.1093/geronj/41.6.778

D’Onofrio, G., D. Sancarlo, F. Addante, F. Ciccone, L. Cascavilla, F. Paris, M. Picoco, C. Nuzzaci, A.C. Elia, A. Greco, R. Chiarini, F. Panza, and A. Pilotto. 2015. Caregiver burden characterization in patients with Alzheimer's disease or vascular dementia. Int. J. Geriatr. Psychiatry 30(9):891-899. https://doi.org/10.1002/gps.4232

Dreamcatcher. n.d. In Wikipedia. Retrieved March 6, 2020 from https://ko.wikipedia.org

Givens, J.L., C. Mezzacappa, T. Heeren, K. Yaffe, and L. Fredman. 2014. Depressive symptoms among dementia caregivers: Role of mediating factors. Am. J. Geriatr. Psychiatry 22(5):481-488. https://doi.org/10.1016/j.jagp.
2012.08.010

Gonzalez, M.T., T. Hartig, G.G. Patil, E.W. Martinsen, and M. Kirkevold. 2010. Therapeutic horticulture in clinical depression: A prospective study of active components. J. Adv. Nurs. 66(9):2002-2013. https://doi.org/10.1111/ j.1365-2648.2010.05383.x

Gonzalez, M.T., T. Hartig, G.G. Patil, E.W. Martinsen, and M. Kirkevold. 2011. A prospective study of group cohesiveness in therapeutic horticulture for clinical depression. Int. J. Ment. Health Nurs. 20(2):119-129. https://doi.org/10.1111/j.1447-0349.2010.00689.x

Harris, K. and J. Trauth. 2020. Horticulture therapy benefits: A report. Int. J. Curr. Sci. Multidiscip. Res. 3(4):61-65.

Hartig, T., R. Mitchell, S. de Vries, and H. Frumkin. 2014. Nature and health. Annu. Rev. Public Health 35:207-228. https://doi.org/10.1146/annurev-publhealth-032013-18 2443

Hernandez, A.M. and S.M. Bigatti. 2010. Depression among older Mexican American caregivers. Cultur. Divers. Ethnic Minor. Psychol. 16(1):50-58. https://doi.org/10.1037/a0 015867

Iavarone, A., A.R. Ziello, F. Pastore, A.M. Fasanaro, and C. Poderico. 2014. Caregiver burden and coping strategies in caregivers of patients with Alzheimer's disease. Neuropsychiatr. Dis. Treat. 10:1407-1413. https://doi.org/10.2147/NDT.S58063

Kamioka, H., K. Tsutani, M. Yamada, H. Park, H. Okuizumi, T. Honda, S. Okada, S.J. Park, J. Kitayuguchi, T. Abe, S. Handa, and Y. Mutoh. 2014. Effectiveness of horticultural therapy: A systematic review of randomized controlled trials. Complement. Ther. Med. 22(5):930-943. https://doi.org/10.1016/j.ctim.2014.08.009

Kim, H.J., B.E. Kim, E.S. Kim, D.E. Shin, S.Y. Lee, and H.L. Jeong. 2016. Correlation of elderly activity level and interpersonal relationship. J. Korean Soc. Community Based Occup. Ther. 6(1):25-32. https://doi.org/10.18598 /kcbot.2016.06.01.03

Kim, J.Y., J.B. Kim, D.Y. Jang, and I.H. Song. 2016. A study on the effect of caregiver burden on suicidal ideation among caregiver for the elderly with dementia. J. Korean Gerontol. Soc. 36(3):883-903.

Kim, K.O. 2017. Exploring pain, life, and meaning of physical activity among dementia caregivers: A photovoice study. Korean J. Phys. Educ. 56(6):11-30. 
https://doi.org/10.23949/KJPE.2017.11.56.6.2

Kim, Y.H., H.O. Bae, and M.R. Huh. 2019. Differences in the effects of a horticultural activity program depending on the level of resilience of college students. J. People Plants Environ. 22(3):255-268. https://doi.org/10.11628/ksppe.2019.22.3.255

Kim, Y.H., H.S. Jo, C.S. Park, K. Kang, E.S. Lee, S.H. Jo, H.O. Bae, and M.R. Huh. 2020. Comparing the effectiveness of the frequency and duration of the horticultural therapy program on elderly women with mild cognitive impairment and mild dementia. J. People Plants Environ. 23(1):35-46. https://doi.org/10.11628/ks ppe.2020.23.1.35

Kim, Y.J., J.W. Han, Y.S. So, J.Y. Seo, K.Y. Kim, and K.W. Kim. 2014. Prevalence and trends of dementia in Korea: A systematic review and meta-analysis. J. Korean Med. Sci. 29(7):903-912. https://doi.org/10.3346/jkms.2 014.29.7.903

Kuo, L.M., H.L. Huang, J. Liang, Y.T. Kwok, W.C. Hsu, P.L. Su, and Y.I.L. Shyu. 2016. A randomized controlled trial of a home-based training programme to decrease depression in family caregivers of persons with dementia. J. Adv. Nurs. 73(3):585-598. https://doi.org/10.1111/jan. 13157

Kwon, J.D. 1994. The change of family relationship caring for the demented elderly and family therapy approaches. Korean J. Fam. Ther. 2(1):1-16.

Kwon, J.D. 1996. Measuring the caregiver burden of caring for the demented elderly. Yonsei Soc. Welf. Rev. 3:140-168.

Kwon, J.D. 2002. Strategies for alleviating the burden and conflicts of the demented family. Yonsei Soc. Welf. Rev. 8:222-239.

Livingston, G., J. Barber, P. Rapaport, M. Knapp, M. Griffin, D. King, D. Livingston, C. Mummery, Z. Walker, J. Hoe, E.L. Sampson, and C. Cooper. 2013. Clinical effectiveness of a manual based coping strategy programme (START, STrAtegies for RelaTives) in promoting the mental health of carers of family members with dementia: Pragmatic randomised controlled trial. BMJ 347:f6276. https://doi.org/10.1136/bmj.f6276

Min, S.K., C.I. Lee, K.I. Kim, S.Y. Suh, and D.K. Kim. 2000. Development of Korean version of WHO Quality of Life Scale Abbreviated Version (WHOQOL-BREF). J Korean Neuropsychiatr. Assoc. 39(3):571-579.
Oh, K.O., M.H. Gang, and K.S. Jung. 2012. Effects of horticultural therapy program on state-anxiety, fatigue and quality of life among women cancer survivors. Asian Oncol. Nurs. 12(2):125-131.

Park, S. and M. Park. 2015. Effects of family support programs for caregivers of people with dementia-caregiving burden, depression, and stress: Systematic review and meta-analysis. J Korean Acad. Nurs. 45(5):627-640. http://dx.doi.org/10.4040/jkan.2015.45.5.627

Park, S.A., A.Y. Lee, K.S. Lee, and K.C. Son. 2014. Gardening tasks performed by adults are moderate-to high-intensity physical activities. HortTechnology 24(1):58-63. https://doi.org/10.21273/HORTTECH.24.1.58

Parks, S.M. and K.D. Novielli. 2003. Alzheimer's disease caregivers: Hidden patients. Clinical Geriatrics 11:34-39.

Perrins-Margalis, N.M., J. Rugletic, N.M. Schepis, H.R. Stepanski, and M.A. Walsh. 2000. The immediate effects of a group-based horticulture experience on the quality of life of persons with chronic mental illness. Occup. Ther. Ment. Health 16(1):15-32. https://doi.org/1 0.1300/J004v16n01_02

Rural Development Administration. 2016, April 11. Air purification plant tilandia. Korea Policy Briefing. Retrieved from http://www.korea.kr/news/visualNewsView.do?ne wsId $=148812122$

Relf, P.D. 1981. Dynamics of horticultural therapy. Rehabil. Lit. 42(5-6):147-150.

Schulz, R., S.R. Beach, S.J. Czaja, L.M. Martire, and J.K. Monin. 2020. Family caregiving for older adults. Ann. Rev. Psychol. 71:635-659. https://doi.org/10.1146/annur ev-psych-010419-050754

Seo, J.Y., J.W. Choi, K.A. Park, and D.Y. Jang. 2018. A convergence study on the effect of caregiving burden on interpersonal problem of dementia caregivers: Focusing on moderating effect of family support. J. Korea Converg. Soc. 9(8):379-392. https://doi.org/10.15207/JKCS.2018. 9.8.379

Siu, A.M.H, M. Kam, and I. Mok. 2020. Horticultural therapy program for people with mental illness: A mixedmethod evaluation. Int. J. Environ. Res. Public Health 17(3):711-726. https://doi.org/10.3390/ijerph17030711

Soga, M., K.J. Gaston, and Y. Yamaura. 2017. Gardening is beneficial for health: A meta-analysis. Prev. Med. Rep. 5:92-99. https://doi.org/10.1016/j.pmedr.2016.11.007 
Sommerfeld, A.J., T.M. Waliczek, and J.M. Zajicek. 2010. Growing minds: Evaluating the effect of gardening on quality of life and physical activity level of older adults. HortTechnology 20(4):705-710. https://doi.org/10.2127 3/HORTTECH.20.4.705

Son, K.C., M.K. Jo, J.E. Song, S.Y. Kim, and S.S. Lee. 2006. Practice of professional horticultural therapy. Seoul, Korea: KuBook from KonKuk University.

Song, M.H., C.S. Park, G.H. Kang, S.S. Lee, and M.R. Huh. 2015. The effect of horticulture therapy program focusing on cultivation about the personal relationship, self-esteem, and mood of chronic schizophrenic patients according to alexithymia levels. J. Korean Soc. People Plants Environ. 18(2):89-96. https://doi.org/10.11628/ks ppe.2015.18.2.089

Statistics Korea. 2018, Dec. 13. Korean social trends 2018 [press release]. Retrieved from http://kostat.go.kr/portal/ korea/kor_nw/1/15/index.board?bmode=read\&aSeq $=37$ 2006

Tanida, M., A. Niijima, J. Shen, T. Nakamura, and K. Nagai. 2005. Olfactory stimulation with scent of essential oil of grapefruit affects autonomic neurotransmission and blood pressure. Brain Res. 1058(1-2):44-55. https://doi.o $\mathrm{rg} / 10.1016 /$ j.brainres.2005.07.048

Töpfer, N.F. and G. Wilz. 2020. Increases in utilization of psychosocial resources mediate effects of cognitivebehavioural intervention on dementia caregivers' quality of life. J. Posit. Psychol. Advance online publication. https://doi.org/10.1080/17439760.2020.1716047

Waelde, L.C., H. Meyer, J.M. Thompson, L. Thompson, and D. Gallagher-Thompson. 2017. Randomized con- trolled trial of inner resources meditation for family dementia caregivers. J. Clin. Psychol. 73(12):1629-1641. https://doi.org/10.1002/jclp.22470

Wasserstein, R.L. and N.A. Lazar. 2016. The ASA statement on p-values: context, process, and purpose. Am. Stat. 70(2):129-133. https://doi.org/10.1080/00031305.2016.1 154108

Yang, M.A., H. Hong, and A. Han. 2019. Interventions for caregivers of people with dementia: A systematic review of randomized controlled trials. Korean J. Occup. Ther. 27(2):67-78. https://doi.org/10.14519/kjot.2019.2 7.2 .06

Yoo, S.H. and C.S. Kim. 2004. An exploratory study on the effects of caregivers' family relationship to the elderly with dementia: Focusing on problems, burden and institutionalization. J. Welfare Aged [Korean J. Gerontol. Soc. Welf.] 26:191-214.

Yoon, B., Y.S. Shim, Y.D. Kim, K.O. Lee, S.J. Na, Y.J. Hong, and D.W. Yang. 2012. Who takes care of patients with dementia in Korea: A study on the present state of patients with dementia living alone and primary caregivers. Dement. Neurocogn. Disord. 11(1):13-17.

Youn, G., B.G. Knight, H. Jeong, and D. Benton. 1999. Differences in familism values and caregiving outcomes among Korean, Korean American and White American dementia caregivers. Psychol. Aging 14(3):355-364. https://doi.org/10.1037//0882-7974.14.3.355

Yun, P.Y. 2018, July 14. Do you know 'tillancia', an air cleaning plant that eats fine dust? The Hankook-Ilbo. Retrieved from https://www.hankookilbo.com/News/Re $\mathrm{ad} / 201807121122080958$ 